\title{
FOSLET 07 - Workshop on Free and Open Source Learning Environments and Tools
}

\author{
Luca Botturi, Riccardo Mazza, Stefano Tardini \\ University of Lugano, eLab - eLearning Lab \\ via Buffi 13, 6900 Lugano, Switzerland \\ \{botturil, mazzar, tardinis\}@lu.unisi.ch \\ http://www.elearninglab.org
}

\section{Introduction}

Web-based Learning Environments supported by Course Management Systems (also known as Learning Management Systems) are nowadays a valid solution for institutions, companies, schools and universities that deliver eLearning or support blended-learning activities. Learning Environments are used to distribute information and content material to learners, prepare and deliver assignments and tests, engage in discussions, and manage distance classes without time and space restrictions.

During the last few years, several institutions have moved from commercial/proprietary solutions to Free and Open Source (FOS) environments. The increasing popularity FOS solutions for eLearning are enjoying is partly due to the absence of license costs, and partly to their great adaptability and interoperability, also in relationship with the development and adoption of Learning Technology Standards, such as the Shareable Content Object Reference Model (SCORM) and the IMS Content Packaging and Learning Design specifications.

However, the integration of FOS solutions for e-learning is not free from some critical issues that demand research.

\section{Why FOS in eLearning?}

What are the main reasons that may push institutions, companies, schools and universities to adopt FOS solutions for their e- and blended learning activities? The perceived benefits of FOS solutions usually concern three aspects, namely costs, infrastructure, and tailoring and integration.

Costs. The issue of costs is particularly relevant when dealing with the choice of an LMS: as a matter of fact, one of the main issues with commercial LMS is funding. The uncertain benefits of online learning may lead an institution to doubt about the 
real return of a huge investment as the acquisition of the required number of seats in a commercial LMS. First, instructors and students may not have established practices in using online tools, so that the actual use of the LMS is unpredictable. Second, the uncertainties of the market and the rapid and often earthshaking developments of the eLearning world may make the commitment to a single producer tricky. Finally, being committed to a commercial LMS risks being a one-shot situation: in the undesired chance of a failure, costs may make almost impossible to try out another solution. Choosing an FOS solution mitigates these three issues. Furthermore, the (almost) complete visibility of the life of an FOS community provides more information about its hope of survival in the eLearning market than the financial reports of super-protected commercial players.

Infrastructure (material and human resources). One of the big issues of FOS software, and one of its major hidden costs, is the need for infrastructure (hardware and network connection) and of in-house work for setting up the system, for maintaining the application and for checking, selecting and installing updates. All of these issues are quite unproblematic in most universities, since they (always) have a dedicated IT staff able to care after the infrastructure, the installation, maintenance and update of software applications. Moreover, the hardware demands of OS software are usually significantly lower than those of commercial software.

Tailoring and integration. An eLearning system potentially impacts the core of a university's activity, and has to be integrated with standard procedures for class scheduling, enrollments, assessment, quality evaluations, network accounting etc. The main advantage that an FOS solution brings to institutional users is the possibility to tailor the application to one's needs, and to integrate it in first person in existing procedures and IT system [2: 125].

\section{FOSLET 07 - The workshop}

In this context, the idea of promoting a workshop on FOS solutions for e- and blended learning activities arose from the experience gained by the authors in two labs of the University of Lugano (USI): the NewMinE Lab (New Media in Education Laboratory: www.newmine.org) and the eLab (eLearning Lab: www.elearninglab.org). In 2004 an OS LMS was introduced in the University of Lugano and in the University of Applied Sciences of Southern Switzerland (SUPSI) in order to support the educational activities and to promote the use of eLearning in the teaching and learning practices of both institutions [1, 2]. Then, in 2006 an OS Learning Objects Repository was developed by eLab and integrated into the LMS (DOOR - Digital Open Objects Repository: http://door.elearninglab.org).

The introduction of e-Courses (this is the name of the platform introduced, based on the Moodle technology; see http://corsi.elearninglab.org) soon raised interesting issues concerning the installation of the platform, its integration into the different existing universities' systems, its customization according to both institutions' needs, the promotion of the new platform among faculty members and students of USI and SUPSI and its evaluation, which showed high satisfaction levels. Hence the interest for other similar experiences and the chance of promoting within the Second 
International Conference on Open Source Systems (OSS 2006) the first FOSLET workshop [3].

FOSLET 07 aims at providing a discussion platform for researchers and practitioners who want to share research findings and experiences about the use of FOS applications for eLearning, in order to identify effective and sustainable solutions, open issues and good practices.

The workshop will focus on solutions, practices, and experience of FOS Learning Environments that give particular emphasis to three perspectives:

1. Interoperability, including course content migration, metadata, and standards implementation.

2. Integration, including LMS support to specific teaching and learning activities, fine-tuning to specific organizational and administrative requirements.

3. Sustainability, including studies about the real cost of software, management issues, long-term financing and reusability.

Specific topics include: interoperability and implementation of standards among Learning Environments; FOS Learning Environments architectures, configurations, and infrastructures; Learning \& Content Management Systems, repositories; metadata models and mapping; interoperability use cases, experience reports of interoperable educational systems; cost models of commercial/proprietary and FOS e-learning solutions; good practices of integration of FOS solutions into real institutional settings.

\section{References}

[1] Botturi, L. Functional Assessment of Some Open Source LMS. eLab Report, Lugano, November 2004.

http://www.elearninglab.org/docs/risorse/report/OS_review_Nov2004.pdf.

[2] Botturi, L., Cantoni, L. and Tardini, S. Introducing a Moodle LMS in Higher Education: the e-Courses Experience in Ticino (Switzerland). Je-LKS. Journal of eLearning and Knowledge Society, Special Issue: C. Giovannella (ed.), Emerging learning environments and Open source in e-learning, 2 (1), March 2006, 123-130. [3] Botturi, L., Mazza, R. and Tardini, S. (eds). FOSLET 2006. Proceedings of the Workshop on Free and Open Source Learning Environments and Tools. University of Lugano - NewMinE ePaper 6, Lugano 2006.

http://www.elab.usilu.net/foslet06/proceedings/NewMinE_ePaper6.pdf. 